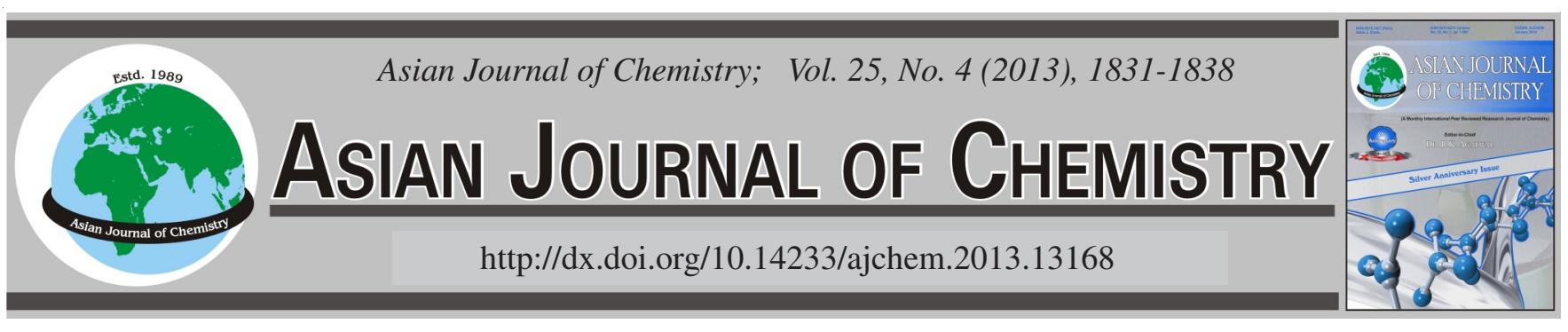

\title{
Comparison of Temperature-Controlled Dispersive and Hollow Fiber Microextraction Techniques Using Ionic Liquid for Determination of Tributyltin and Triphenyltin in Water
}

\author{
Hossein Sheikhloie ${ }^{1, *}$, Mohammad Saber Tehrani ${ }^{2}$ and Syed WaqIF Husain ${ }^{2}$
}

${ }^{1}$ Department of Basic Sciences, Maragheh Branch, Islamic Azad University, Maragheh, Iran

${ }^{2}$ Department of Chemistry, Science and Research Branch, Islamic Azad University, Tehran, Iran

*Corresponding author: Fax: +98 421 3257338; Tel: +98 9143221014; E-mail: H.Sheikhloie@iau-maragheh.ac.ir; H_sheikhloie@yahoo.com

\begin{abstract}
Two liquid phase microextraction techniques termed ionic liquid based hollow fiber liquid phase microextraction and temperaturecontrolled ionic liquid dispersive liquid phase microextraction have been compared for the analysis of tributyltin and triphenyltin in environmental water samples by high performance liquid chromatography fluorimetric detection. Experimental conditions have been investigated for both methods. Under the optimal conditions, the limits of detection for tributyltin and triphenyltin obtained by ionic liquid based hollow fiber liquid phase microextraction and temperature-controlled ionic liquid dispersive liquid phase microextraction | were ranged from 0.46 to $0.72 \mu \mathrm{g} / \mathrm{L}$ and 0.24 to $0.32 \mu \mathrm{g} / \mathrm{L}$ and the relative standard deviations (RSDs, $\mathrm{n}=5$ ) were in the range of 6.8 $0.72 \%$ and 2.6-3.1\%, respectively. Both methods were found to be simple, fast, efficient and inexpensive. Compared with ionic liquid based hollow fiber liquid phase microextraction, the advantages of temperature-controlled ionic liquid dispersive liquid phase microextraction technique were less extraction time. Both methods were applied to the analysis of tributyltin and triphenyltin in sea water, waste water and river water.
\end{abstract}

Key Words: Hollow fiber, Dispersive microextraction, Ionic liquid, HPLC, Tributyltin, Triphenyltin.

\section{INTRODUCTION}

During the past few decades, wide spread use of organotin compounds [mainly trisubstituted forms, tributyltin and triphenyltin)] has led to their entry into the environment. So that European Union has listed them as priority pollutants ${ }^{1}$. Despite their toxicity, especially in the form of chloride complexes they are widely used in industry and agriculture as catalyser, biocides, polymer stabilizer and active ingredient in antifouling paints. Consequently, they can be found in natural waters and sediments at concentration levels that may exert sublethal and even lethal effects on aquatic organisms and mammals $^{2,3}$. For instance tributyltin has been identified as an endocrine disruptor at very low concentration in water. Therefore, monitoring of organotin compounds in environmental water at extremely low concentration is an important issue, which requires simple, fast and highly sensitive analytical techniques.

Despite sophisticated instruments for analysis of tributyltin and triphenyltin and the complexity of the environmental samples, direct determination, especially at low concentrations in complex matrices is often difficult. Therefore, sample preparation step for clean up and concentrate the analytes is usually required prior to the instrumental determination. Liquidliquid extraction ${ }^{4}$, solid-phase extraction ${ }^{5}$ and supercritical fluid extraction ${ }^{6}$ are the most commonly used techniques. However, extraction or elution, often require an appreciable amount of toxic solvent, which are hazardous to the operators and a threat to the environment or high cost special apparatus. Therefore, a variety of microextraction techniques that use no amounts of solvent were developed. Solid-phase microextraction $^{7}$ and stir bar sorptive extraction ${ }^{8}$ are the typical extraction techniques for analysis of organotin compounds. Solid-phase microextraction has some drawbacks such as limited lifetime, fragility of fibres and possibility of sample carry-over between analyses ${ }^{7}$. Stir bar sorptive extraction also requires a special apparatus for desorption of the extracted analytes; the application of stir bar sorptive extraction are restricted by the limited commercial available coatings and carry-over effect cannot be ignored either.

Recently, liquid phase microextraction (LPME) has attracted increasing attention as a novel sample preparation technique including single drop microextraction (SDME), in which the extractant phase is a drop of water-immiscible solvent suspended in the aqueous sample or in the headspace of the sample $\mathrm{e}^{9,10}$. Hollow fiber based liquid phase microextraction (HF-LPME), where the target analytes are extracted from aqueous samples into a supported liquid membrane 
(SLM) sustained in the pores of a polypropylene hollow fiber and further into an acceptor phase present inside the lumen of the hollow fiber. The acceptor phase can be organic, providing a two-phase extraction system or aqueous resulting in a threephase system ${ }^{11,12}$ and dispersive liquid-liquid microextraction (DLLME), which is based on the ternary component solvent system $^{13-15}$, like homogeneous liquid-liquid extraction (HLLE) and cloud point extraction (CPE).

Dispersive liquid-liquid microextraction has been developed as a high-performance, powerful, simple, rapid and inexpensive microextraction method by Assadi and co-workers ${ }^{13}$. The basic principle of this method is dispersion of extraction solvent (immiscible in water) assisted with disperser solvent (miscible in both water and extraction solvents) within aqueous solution, which lead to very high contact area between aqueous phase and extraction solvent. However, the amount of disperser solvent used is relatively high, so it may lead to decrease the extraction recovery of less hydrophobic compounds. Therefore, a new microextraction method was designed and termed as temperature-controlled ionic liquid dispersive liquid phase microextraction (TCILDLPME) ${ }^{16}$. Unlike the DLLME technique described above, the TCILDLPME method is a binary component system comprising water and ionic liquid, no disperser solvent is used and dissolution of ionic liquid depends on the temperature. Ionic liquids are ionic medium resulting from combination of organic cations and various anions and may be liquid at room temperature. They have been considered as green solvents ${ }^{17}$. They comprise low vapour pressure, high thermal stability, tunable viscosity and the miscibility with water and other organic solvents. On the other hand, due to their low volatility, flammability and toxicity, ionic liquids are designable according to the need for use ${ }^{18-25}$. Analytical applications of ionic liquids have been reviewed by few researchers ${ }^{26-29}$. We have recently demonstrated, the applicability of 1-butyl-3-methylimiazolium hexafluorophosphate $\left(\left[\mathrm{C}_{4} \mathrm{MIM}\right]\left[\mathrm{PF}_{6}\right]\right)$ ionic liquid as extraction solvent in head space-SDME employing HPLC-fluorimetric system for the determination of tributyltin and triphenyltin in environmental water samples ${ }^{30}$.

The aim of this study was to investigate the possibility of ionic liquid in pre-concentration of tributyltin and triphenyltin in water samples using HFLPME and TCILDLPME techniques and comparing the obtained results. The effects of various experimental parameters on the extraction were investigated in each method and operating conditions were also optimized. To evaluate the applicability of the proposed methods, they were then applied for the analysis of environmental water samples.

\section{EXPERIMENTAL}

The Accurel ${ }^{\circledR}$ Q 3/2 polypropylene hollow fibre membranes (200 $\mu \mathrm{m}$ wall thickness, $600 \mu \mathrm{m}$ inner diameter and $0.2 \mu \mathrm{m}$ pore size) were obtained from Membrana $\mathrm{GmbH}$ (Wuppertal, Germany). Tributyltin chloride (tributyltin, $96 \%$ ), triphenyltin chloride (triphenyltin, $95 \%)$ and fisetin (3,3',4',7-tetrahydroxyflavone were obtained from Aldrich (Steinheim, Germany) and were used without further purification. Methanol HPLC-grade, sodium chloride, triethylamine (TEA), Brij-35 (non-ionic surfactant) and succinic acid disodium salt were from Merck (Darmstadt, Germany). Synthesis-grade ionic liquid, 1-hexyl-3- methylimidazolium hexafluorophosphate ([ $\left.\mathrm{C}_{6} \mathrm{MIM}\right]\left[\mathrm{PF}_{6}\right]$ ) was obtained from Fluka (Buchs, Switzerland). The water used for preparing the aqueous solution was high purity deionized water. Stock standard solutions of tributyltin and triphenyltin $\left(500 \mathrm{mgL}^{-1}\right.$ tin) were prepared by dissolving the corresponding chloride salts in methanol and stored at $4{ }^{\circ} \mathrm{C}$ in dark glass bottles. Working standard solutions $\left(10 \mathrm{mg} \mathrm{L}^{-1}\right)$ were prepared weekly by dilution of the stock solutions in methanol and subsequent dilutions were freshly prepared. A $1 \mathrm{M}$ acetate buffer ( $\mathrm{pH}$ ) was prepared by dissolving $8.85 \mathrm{~g}$ sodium acetate in $100 \mathrm{~mL}$ of deionized water and $2 \mathrm{~mL}$ glacial acetic acid was added. All solutions were stored in the dark at $4{ }^{\circ} \mathrm{C}$ and all glassware used for experiments were previously soaked in $10 \%(\mathrm{v} / \mathrm{v})$ nitric acid for $24 \mathrm{~h}$ and rinsed with deionized water prior to use.

Organotin compounds are non-fluorescent compounds. Therefore, fluorogenic reagent was used for LC fluorimetric detection consisted of a $5 \times 10^{-5} \mathrm{M}$ fisetin, $0.5 \%(\mathrm{w} / \mathrm{v})$ Brij-35 and $0.2 \mathrm{M}$ succinic acid disodium salt solution in water. Fluorogenic reagent merges with the chromatographic effluent $(2 \mathrm{~mL} \mathrm{~min}-1)$ in a T-tube before its introduction into a fluorescence detector.

A $25 \mu \mathrm{L}$ microsyringe (Hamilton, switzerland) with a needle of $0.5 \mathrm{~mm}$-outer diameter was used to introduce the acceptor into the lumen of the hollow fiber for extraction and injection of the acceptor into HPLC system after extraction. A magnetic stirrer (Heidolph MR 3003 Germany) and a (8 mm $\times 3 \mathrm{~mm}$ ) magnetic stirring bar were used to stir the solution. Glass test tube and screw cap conical bottomed were used as extraction vessels or sample vials. A Waters (Milford, MA 01757, USA) liquid chromatography (LC) system equipped with a Breeze 1525 Binary HPLC pump and 2475 multi $\lambda$ fluorescence detection was used. The excitation and emission wavelengths of the detector were set at 412 and $496 \mathrm{~nm}$, respectively. Fluorescent derivatives of analytes were prepared using a post column reaction module and a personal computer equipped with a Breeze program for LC system was used to acquire and process chromatographic data. A 7725i Rheodyne injector (Rohnert Park, CA, USA) and a reversed phase VP$\mathrm{ODS} \mathrm{C}_{18}$ column $(250 \mathrm{~mm} \times 4.6 \mathrm{~mm}$ i.d., particle size $4 \mu \mathrm{m})$ with a guard column were also used for injection and separation of the target analyte, respectively. The mobile phase consisted of $0.03 \%(\mathrm{v} / \mathrm{v})$ TEA in methanol-water $(85: 15, \mathrm{v} / \mathrm{v})$. It was filtered through a $0.45 \mu \mathrm{m}$ membrane filter and degassed for $15 \mathrm{~min}$ in an ultrasonic batch before use. All chromatographic separations were carried out at room temperature using $0.6 \mathrm{~mL} \mathrm{~min}{ }^{-1}$ mobile phase flow rate. Measurements of $\mathrm{pH}$ were made with a metrohm $\mathrm{pH}$ meter model: 691(Herisau, Switzereland) using a combined glass electrode. Phase separation was conducted with a Universal 320R refrigerated centrifuge and a Jeio Tech BW-05G water bath (Kirchengern, Germany) used for heating.

HF-LPME procedure: The hollow fiber was cut into $2 \mathrm{~cm}$ long pieces. These pieces were ultrasonically cleaned with acetone, air-dried and stored in a closed glass tube. For extraction, $5 \mu \mathrm{L}$ aliquot of ionic liquid $\left(\left[\mathrm{C}_{4} \mathrm{MIM}\right]\left[\mathrm{PF}_{6}\right]\right)$ as organic acceptor was taken into $25 \mu \mathrm{L}$ HPLC syringe. The needle of microsyringe was inserted into a hollow fiber 
segment and $5 \mu \mathrm{L}$ of the solvent was injected so that the lumen of the fiber was filled. The hollow fiber was immersed into the ionic liquid for $20 \mathrm{sec}$ for further impregnation of the hollow fiber pores with ionic liquid. The hollow fiber was removed from the solvent and rinsed with clean water for the elimination of possible surplus ionic liquid on the hollow fiber surface. However, $5 \mathrm{~mL}$ of sample solution (deionized water or environmental water) containing tributyltin and triphenyltin at the concentration level of $10 \mu \mathrm{gL}^{-1}$ was transferred into a glass vial, $1 \mathrm{~mL}$ of acetate buffer $(\mathrm{pH} 5)$ and $1 \mathrm{~mL}$ of $5 \%$ $\mathrm{NaCl}(\mathrm{w} / \mathrm{v})$ were added. Then, the prepared hollow fiber was immersed into the sample. The sample vial was put on spot of a magnetic stirring device. Extraction took place between the sample solution and the solvent in the hollow fiber during 25 $\mathrm{min}$ at a magnetic rotation speed of $900 \mathrm{rpm}$. After extraction, the extraction solvent was withdrawn and directly injected into the HPLC for analysis. A new piece of hollow fiber was used for each extraction.

Temperature controlled ionic liquid dispersive liquid phase microextraction procedure: In this procedure, $10 \mathrm{~mL}$ of water sample (ultra pure water or environmental water) containing tributyltin and triphenyltin at the concentration level of $10 \mu \mathrm{gL}-1$ and $2 \mathrm{~mL}$ of acetate buffer ( $\mathrm{pH} 5,1 \mathrm{M}$ ), was transferred to a screw cap conical bottomed glass test tube. $10 \mu \mathrm{L}$ of 1-hexyl-3-methylimidazolium hexafluorophosphate $\left(\left[\mathrm{C}_{6} \mathrm{MIM}\right]\left[\mathrm{PF}_{6}\right]\right)$ as extraction solvent was injected rapidly into the aqueous solution with a $25 \mu \mathrm{L}$ microsyringe (Hamilton, switzerland). Then the conical test tube was heated in a water bath at the temperature of $35^{\circ} \mathrm{C}$ for $4 \mathrm{~min}$. The ionic liquid was dissolved completely and mixed with the solution. Afterward, the tube was cooled with ice water for $5 \mathrm{~min}$, the solution became cloudy and the analytes extracted into the ionic liquid phase. Then the solution was centrifuged for $5 \mathrm{~min}$ at 4000 rpm. As a result, the fine droplets of ionic liquid settled at the bottom of the tube. Bulk aqueous phase was removed simply by a syringe. Afterwards, ionic liquid-phase was dissolved in $50 \mu \mathrm{L}$ mobile phase (MeOH: $\mathrm{H}_{2} \mathrm{O}, 85: 15$, v/v) and $5 \mu \mathrm{L}$ of it was injected into the HPLC system for analysis.

Environmental water samples: Environmental water samples such as seawater, wastewater and river water were collected for validating the proposed method. The sea water samples obtained from a trading port in south of Iran. Wastewater sample was collected from industrial area in south-west of Tabriz-Iran. River water sample was obtained from southwest Iran. The collected water samples were kept in dark glass bottles, at a temperature of $4{ }^{\circ} \mathrm{C}$.

\section{RESULTS AND DISCUSSION}

Hollow fiber-liquid phase microextraction: The first aim of this study was to optimize hollow fiber liquid phase microextraction sampling conditions for the extraction of tributyltin and triphenyltin from water samples. Parameters such as extraction solvent, extraction time, stirring rate, salt content, sample $\mathrm{pH}$ and sample volume were optimized. Selecting the most suitable extraction solvent as the acceptor phase is an important step in hollow fiber liquid phase microextraction. According to the properties of $\left(\left[\mathrm{C}_{4} \mathrm{MIM}\right]\left[\mathrm{PF}_{6}\right]\right)$ ionic liquid such as being immiscible with water, low volatility, high polarity $^{31}$ and high solubility for the target analytes, it can be used as acceptor phase for the extraction of tributyltin and triphenyltin. In addition, $\left(\left[\mathrm{C}_{4} \mathrm{MIM}\right]\left[\mathrm{PF}_{6}\right]\right)$ ionic liquid is compatible with direct injection into the HPLC column. Meanwhile, the polarity of $\left(\left[\mathrm{C}_{4} \mathrm{MIM}\right]\left[\mathrm{PF}_{6}\right]\right)$ is similar to the polarity of poly propylene fiber, so that, it can be easily immobilized within the pores of the hollow fiber ${ }^{32}$. Therefore, the $\left(\left[\mathrm{C}_{4} \mathrm{MIM}\right]\left[\mathrm{PF}_{6}\right]\right)$ ionic liquid was adopted in the following study.

Mass transfer is a time dependent process and its rate is reduced as the system reaches equilibrium conditions. Hence, extraction efficiency depends on the length of the extraction time. HF-LPME is an equilibrium process rather than an exhaustive extraction. It requires a period for equilibrium to be established. However, it is not normally practicable to use extraction time sufficiently long for equilibrium to be attained. Therefore, the extraction time was studied with respect to extraction efficiency. As shown in Fig. 1, 25 min was selected as the suitable time.

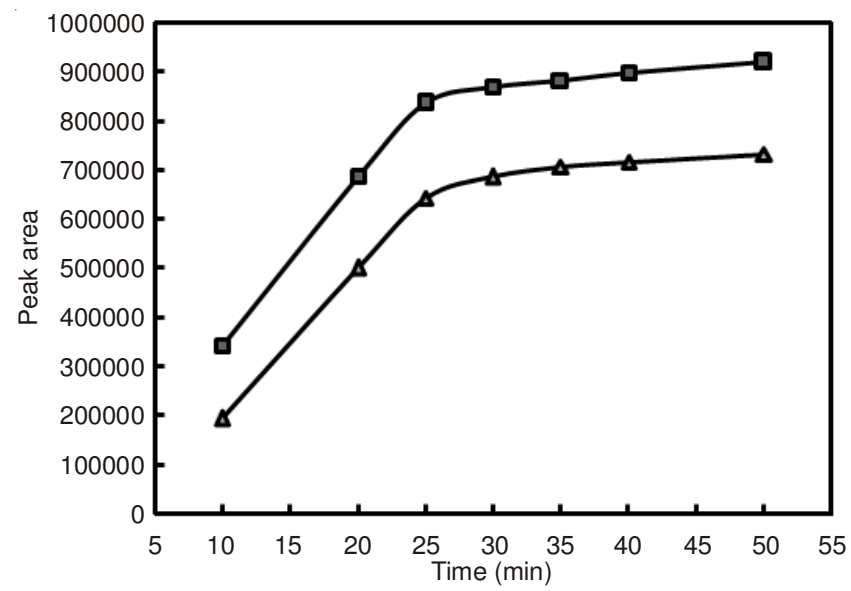

Fig. 1. Effect of extraction time on extraction efficiency of HF-LPME with $5 \mu \mathrm{L}\left(\left[\mathrm{C}_{4} \mathrm{MIM}\right]\left[\mathrm{PF}_{6}\right]\right)$ ionic liquid as solvent. Concentration, $20 \mu \mathrm{g}$

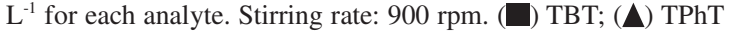

Magnetic stirring provides a fresh donor phase for extraction to the ionic liquid in the pores of the hollow fiber and then into the ionic liquid inside the lumen of the fiber. The analyte molecules are able to pass through the boundary layer of the hollow fiber more easily, thereby increasing the efficiency of extraction. However, under high-speed agitation, air bubbles generated on the surface of the hollow fiber reduce the precision of the method. Therefore, the selected stirring speed was $900 \mathrm{rpm}$.

Fig. 2 shows the effect of ionic strength on the extraction efficiency. It was observed that the extraction of the tributyltin and triphenyltin will be reaching the maximum if aqueous solution contained $5 \% \mathrm{NaCl}$. In aqueous solution, sodium chloride merely is in ionic form and its role in the extraction is to increase the ionic strength of the donor solution and decrease the solubility of tributyltin and triphenyltin. Therefore, the extraction efficiency would be improved, because of the salting-out effect. In other words, at high ionic strength, the solubility of organotin compounds would be increased, as a result of common ion effect. Then, the extraction efficiency was reduced. 


\begin{tabular}{|c|c|c|c|c|c|c|}
\hline \multicolumn{7}{|c|}{$\begin{array}{l}\text { TABLE-1 } \\
\text { PERFORMANCE OF IL- HF-LPME-HPLC-FLUORIMETRY FOR DIRECT DETERMINATION } \\
\text { OF TRIBUTYLTIN AND TRIPHENYLTIN IN WATER SAMPLES }\end{array}$} \\
\hline Compound & $\begin{array}{c}\text { Linear range } \\
\left(\mu \mathrm{gL}^{-1}\right)\end{array}$ & Regression equation & $\begin{array}{c}\text { Correlation } \\
\text { coefficient }\left(\mathrm{R}^{2}\right)\end{array}$ & $\begin{array}{c}\text { LOD } \\
\left(\mu \mathrm{L} \mathrm{L}^{-1}, \mathrm{~S} / \mathrm{N}=3\right)\end{array}$ & $\begin{array}{c}\text { RSD } \\
(\%, \mathrm{n}=5)\end{array}$ & $\begin{array}{c}\text { Recovery } \\
(\%)\end{array}$ \\
\hline Tributyltin & $1-150$ & $y=30902 x+20068$ & 0.991 & 0.46 & 6.8 & $95.2 \pm 4.1^{\mathrm{a}}$ \\
\hline Triphenyltin & $1-150$ & $y=22209 x+19431$ & 0.990 & 0.72 & 7.4 & $89.6 \pm 5.3^{\mathrm{a}}$ \\
\hline
\end{tabular}

The influence of the $\mathrm{pH}$ of the donor solution on the extraction of tributyltin and triphenyltin in the range of 2 to 12 was studied. The extraction of tributyltin and triphenyltin were increased dramatically when the $\mathrm{pH}$ value was increased from 2 to 5 and then remained nearly constant across the range of 5-12. This can be explained on the basis of acidity constants $\left(\mathrm{pK}_{\mathrm{a}}\right)$ of tributyltin and triphenyltin, which are 6.25 and 5.20 for tributyltin and triphenyltin, respectively ${ }^{33}$. The $\mathrm{pK}_{\alpha}$ values of the analytes are $>5$. They would be protonated at $\mathrm{pH}$ below 5 , which will make them much more partitioned into the aqueous phase. Thus, in acidic solution, their extraction efficiencies were very low. At $\mathrm{pH}=5$ they may exist as neutral molecules and were easily extracted. In general, $\mathrm{pH}=5$ was conducive for extraction of tributyltin and triphenyltin. Therefore, the $\mathrm{pH}$ of the sample solution as donor phase was maintained at 5 by $1 \mathrm{M}$ acetate buffer.

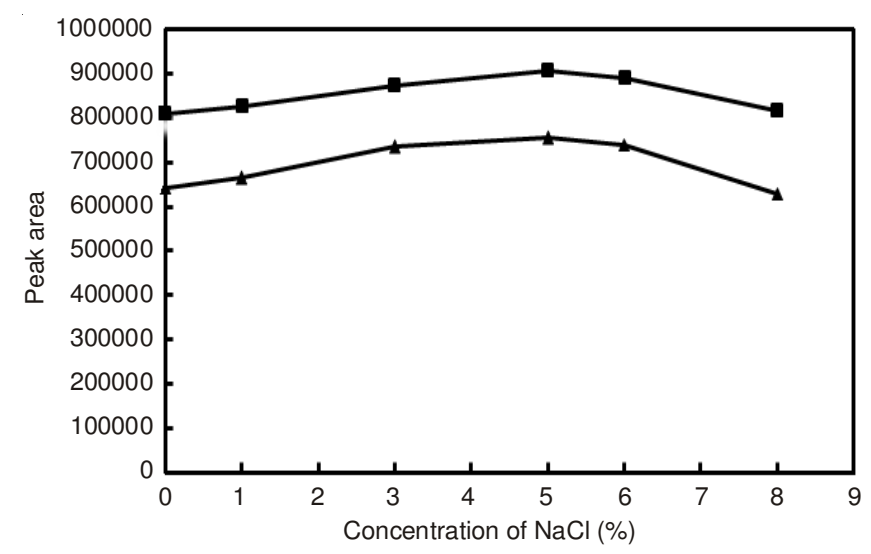

Fig. 2. Effect of sodium chloride on extraction efficiency of HF-LPME with $5 \mu \mathrm{L}\left(\left[\mathrm{C}_{4} \mathrm{MIM}\right]\left[\mathrm{PF}_{6}\right]\right)$ ionic liquid as solvent. Concentration, $20 \mu \mathrm{g} \mathrm{L}^{-1}$ for each analyte. Extraction time: $25 \mathrm{~min}$, stirring rate:

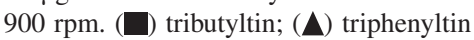

The volumes of the donor and acceptor phases should be selected taking into account some considerations. In general, the sensitivity of the method can be increased by decreasing the volume ratio of the acceptor-to-donor phase ${ }^{34}$. However, the volume of the acceptor solution used for extraction may also be adjusted, depending on the analytical technique coupled to HF-LPME ${ }^{35}$. Therefore, for complete immersion of the HF-LPME in sample solution and employing HPLC system, $5 \mathrm{~mL}$ sample solution as donor phase and $5 \mu \mathrm{L}$ ionic liquid as acceptor phase was used to provide lower detection limit ${ }^{34}$. Then, the method was evaluated for accuracy, precision and limits of detection (Table-1). Calculated recoveries of the target analytes throughout the whole procedure were between 89.6 and $95.2 \%$.
Temperature-controlled ionic liquid dispersive liquid phase microextraction: In TCILDLPME method, ionic liquid was injected into the sample solution and dispersed entirely into the solution as infinitesimal drops under a set condition. This allows the contact area of the droplets to be enlarged appreciably and the drop volume can also be changed in a wide range. Hence, the sensitivity of the proposed method can be tuned with a series of parameters. This method was developed based on this concept and 1-hexyl-3-methylimidazolium hexafluorophosphate was selected as suitable extraction solvent, because it is immiscible with water, relatively inexpensive, extraction capability for tributyltin and triphenyltin, higher density than water and compatible with HPLC. Furthermore, it has very low vapour pressure and is a green solvent.

The effect of ionic liquid volume on the extraction efficiency was studied by dissolving a certain volume of $\left(\left[\mathrm{C}_{6} \mathrm{MIM}\right]\left[\mathrm{PF}_{6}\right]\right)$ in aqueous sample under the described procedure. Results indicated that the extraction efficiency of two compounds increased with the ionic liquid volume over the range of 30-50 $\mu \mathrm{L}$ and decreased over the range of 50-60 $\mu \mathrm{L}$. The best extraction efficiency was obtained at $50 \mu \mathrm{L}$. Less efficient extraction might be produced by the larger volume, because the ionic liquid adsorbed to the wall of the tube and part of analytes migrating into these ionic liquid and not be centrifuged into the bottom of the tube. At the same time, part of the ionic liquid would be dissolved in the aqueous solution, which leads to losses of analytes. According to the results, $50 \mu \mathrm{L}$ of ionic liquid was chosen as optimum volume.

Liquid phase microextraction is an equilibrium process and sufficient time is needed for the system to reach equilibrium. The extraction time means the time from the moment the solution containing dissolved ionic liquid was put into ice water bath to the set interval. Results shown in Fig. 3, demonstrates that the extraction efficiency increased for the studied analytes in the first $5 \mathrm{~min}$ and then increased very little over the time range of 5-10 min. Therefore, $5 \mathrm{~min}$ was adopted as the optimal condition. It is revealed that the surface area between extraction solvent and aqueous phase (sample) is much large. Thereby, transfer of analytes from aqueous phase (sample) to extraction phase is fast. Subsequently, equilibrium state is achieved quickly and consequently, the extraction time is very short. This is the most important advantage of the proposed method.

Temperature is the driving force for the complete dispersion of $\left(\left[\mathrm{C}_{6} \mathrm{MIM}\right]\left[\mathrm{PF}_{6}\right]\right)$ into the aqueous solution, because ionic liquids are dispersed more easily at the temperature above $30^{\circ} \mathrm{C}$. Therefore, it plays an important role on the extraction efficiency of tributyltin and triphenyltin in water samples. A series of experiments were designed for the optimization of 


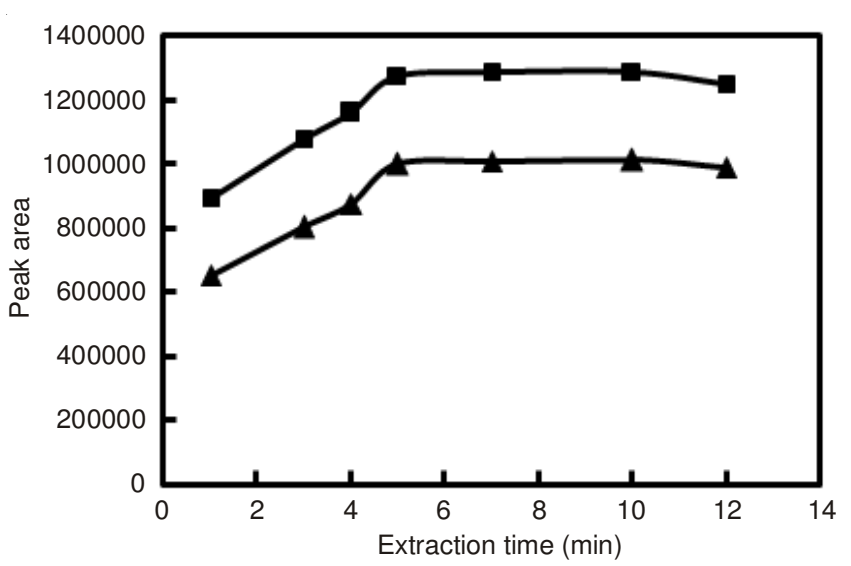

Fig. 3. Effect of extraction time on the extraction efficiency. Concentration of each analyte: $10 \mu \mathrm{g} \mathrm{mL} \mathrm{m}^{-1}$; sample volume: $10 \mathrm{~mL}$; volume of $\left[\mathrm{C}_{6} \mathrm{MIM}\right]\left[\mathrm{PF}_{6}\right]: 50 \mu \mathrm{L}$; temperature: $40{ }^{\circ} \mathrm{C}$; centrifugation time: 5

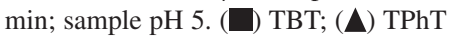

temperature and the results are recorded in Fig. 4. As shown the extraction efficiency was maximum at $35^{\circ} \mathrm{C}$ and then was decreased at higher temperatures. Since, the solubility of tributyltin and triphenyltin in aqueous solutions would be increased with increase in temperature ${ }^{36}$.

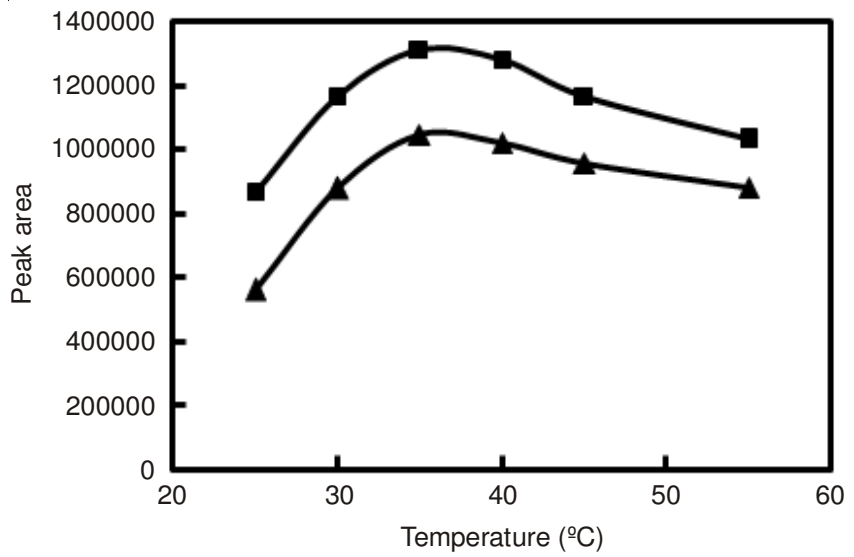

Fig. 4. Effect of temperature on the extraction efficiency. Concentration of each analyte: $10 \mu \mathrm{g} \mathrm{mL}^{-1}$; sample volume: $10 \mathrm{~mL}$; volume of $\left[\mathrm{C}_{6} \mathrm{MIM}\right]\left[\mathrm{PF}_{6}\right]: 50 \mu \mathrm{L}$; extraction time: $5 \mathrm{~min}$; centrifugation time:

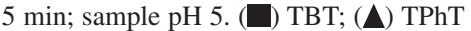

The effect of salt concentration on the microextraction of triorganotin was investigated. In general, the extraction of the tributyltin and triphenyltin reach to maximum when aqueous solution contains $5 \%$ sodium chloride. In aqueous solution, $\mathrm{NaCl}$ is only in ionic form and small amount of salt cause to increase the ionic strength of the sample solution and decrease the solubility of tributyltin and triphenyltin. Consequenlty, the extraction efficiency would be enhanced because of the salting- out effect. But, if large amount of salt is added, ion exchange occurs between $\left(\left[\mathrm{C}_{6} \mathrm{MIM}\right]\left[\mathrm{PF}_{6}\right]\right)$ and chloride, which makes $\left[\mathrm{C}_{6} \mathrm{MIM}\right] \mathrm{Cl}$ soluble in water. This process might lead to the either decrease of the amount of settled ionic liquid phase, or poor extraction performance. Therefore, $5 \% \mathrm{NaCl}$ was selected in the further study.

Centrifugation controls the phase separation and is a crucial step in proposed method. In general, a higher rate of centrifugation can lead to a shorter centrifugation time. So the maximum rate of $4000 \mathrm{rpm}$ was used in the experiments. In order to reach the best extraction efficiency, centrifugation time was investigated and ionic liquid-phase transferred completely to the bottom of centrifuge tube after 4 min of centrifugation. Consequently, the optimum centrifugation time was chosen as 5 min.

Quality characteristics of the TCILDLPME method, for example linear range, correlation coefficient, precision and detection limit were calculated for these optimum conditions. The results are given in Table-2. The linear ranges were investigated over a concentration range of $0.5-200 \mathrm{gL}^{-1}$ for tributyltin and triphenyltin. The precisions were obtained by five reduplicate extractions of a $10 \mu \mathrm{gL}^{-1}$ spiked water samples. RSD ranged from 2.6 to $3.1 \%$ for tributyltin and triphenyltin, respectively. Detection limits were obtained based on a signalto-noise ratio $(\mathrm{S} / \mathrm{N})$ of 3 using double-distilled water spiked with tributyltin and triphenyltin at $10 \mu \mathrm{gL}^{-1}$ spiked level and were found for tributyltin and triphenyltin to be 0.24 and 0.32 $\mu \mathrm{gL}^{-1}$, respectively.

Comparison of the methods: The optimized HF-LPME procedure was compared with TCILDLPME. Extraction of natural, industrial water and analysis of tributyltin and triphenyltin is possible by both methods. In terms of extraction time, HF-LPME and TCILDLPME are equilibrium techniques, which enable determination of these target compounds in 25 min and less than $5 \mathrm{~min}$, respectively. Therefore, in TCILDLPME technique, the transition of the analyte from aqueous phase (sample) to extraction phase can be very fast and the equilibrium state can be subsequently achieved very quickly, resulting in a very short extraction time needed for equilibrium. Short extraction time is a remarkable advantage of the TCILDLPME technique. Performance data for the two techniques are listed in Table- 3 and compared with HS-SDME using ( $\left[\mathrm{C}_{4} \mathrm{MIM}\right]\left[\mathrm{PF}_{6}\right]$ ) ionic liquid as extraction solvent in the determination of tributyltin and triphenyltin in environmental water samples ${ }^{29}$. As it is shown, some differences are apparent. Repeatability, expressed as RSD, was better for TCILDLPME than the HFLPME and HS-SDME. Meanwhile, recovery was higher for TCILDLPME, possibly because of the large volume of ionic liquid in the aqueous solution. Matrix effects do not adversely affect quantitative determination by three methods

TABLE-2

PERFORMANCE OF TCILDLPME-HPLC-FLUORIMETRY FOR DETERMINATION OF TRIBUTYLTIN AND TRIPHENYLTIN IN WATER SAMPLES

\begin{tabular}{ccccccc}
\hline Compound & $\begin{array}{c}\text { Linear range } \\
\left(\mu \mathrm{gL}^{-1}\right)\end{array}$ & $\begin{array}{c}\text { Regression } \\
\text { equation }\end{array}$ & $\begin{array}{c}\text { Correlation } \\
\text { coefficient }\left(\mathrm{R}^{2}\right)\end{array}$ & $\begin{array}{c}\text { LOD }\left(\mu \mathrm{g} \mathrm{L} \mathrm{L}^{-1},\right. \\
\mathrm{S} / \mathrm{N}=3)\end{array}$ & $\begin{array}{c}\text { RSD } \\
(\%, \mathrm{n}=5)\end{array}$ & $\begin{array}{c}\text { Recovery } \\
(\%)\end{array}$ \\
\hline Tributyltin & $0.5-200$ & $\mathrm{y}=96319 \mathrm{x}+47014$ & 0.998 & 0.24 & 2.6 & $100.1 \pm 1.8^{\mathrm{a}}$ \\
Triphenyltin & $0.5-200$ & $\mathrm{y}=92106 \mathrm{x}+32681$ & 0.996 & 0.32 & 3.1 & $97.2 \pm 2.6^{\mathrm{a}}$ \\
\hline
\end{tabular}

a. Mean value \pm standard deviation $(\mathrm{n}=3)$; TCILDLPME conditions: concentration of each analyte: $10 \mu \mathrm{g} \mathrm{mL}{ }^{-1}$; sample volume: $10 \mathrm{~mL}$; volume of $\left[\mathrm{C}_{6} \mathrm{MIM}\right]\left[\mathrm{PF}_{6}\right]: 50 \mu \mathrm{L}$; sample $\mathrm{pH}$ 5; extraction time: $5 \mathrm{~min}$; temperature: $35^{\circ} \mathrm{C} ; 5 \% \mathrm{NaCl}$; centrifugation time: 5 min 


\begin{tabular}{|c|c|c|c|}
\hline \multicolumn{4}{|c|}{$\begin{array}{c}\text { TABLE-3 } \\
\text { COMPARISON OF IL-HF-LPME, TCILDLPME AND IL-HS-SDME METHODS FOR } \\
\text { DETERMINATION OF TRIBUTYLTIN AND TRIPHENYLTIN IN WATER }\end{array}$} \\
\hline & IL-HF-LPME & TCILDLPME & IL-HS-SDME \\
\hline Sample consumption (mL) & 5 & 10 & 6 \\
\hline Extraction solvent volume $(\mu \mathrm{L})$ & 5 & 50 & 10 \\
\hline Extraction time (min) & 25 & 5 & 30 \\
\hline Enrichment factor & $87.4-95.4$ & $194.4-200.2$ & $68.2-82.1$ \\
\hline Accuracy (recovery, \%) & $89.6-95.2$ & $97.2-100.1$ & $86.9-92.1$ \\
\hline Repeatability (RSD, \%, n = 5) & $6.8-7.4$ & 2.6-3.1 & $7.8-8.3$ \\
\hline Linearity $\left(\mathrm{R}^{2}\right)$ & $>0.990$ & $>0.996$ & $>0.990$ \\
\hline Sensitivity (LOD; $S / N=3, \mu \mathrm{g} \mathrm{L}^{-1}$ ) & $0.46-0.72$ & $0.24-0.32$ & $0.62-0.95$ \\
\hline Linear range $\left(\mu \mathrm{g} \mathrm{L}^{-1}\right)$ & $1-150$ & $0.5-200$ & $1-100$ \\
\hline Applicability & $\begin{array}{l}\text { Biological and environmental } \\
\text { samples }\end{array}$ & $\begin{array}{l}\text { Biological and environmental } \\
\text { samples }\end{array}$ & $\begin{array}{l}\text { Biological and environmental } \\
\text { samples }\end{array}$ \\
\hline Reference & Represented method & Represented method & {$[28]$} \\
\hline
\end{tabular}

\begin{tabular}{|c|c|c|c|c|c|c|}
\hline \multicolumn{7}{|c|}{$\begin{array}{c}\text { TABLE-4 } \\
\text { DETERMINATION OF TBT AND TPhT IN VARIOUS ENVIRONMENTAL WA }\end{array}$} \\
\hline \multirow{2}{*}{ Analyte } & \multirow{2}{*}{ Sample } & \multirow{2}{*}{$\begin{array}{c}\text { Added } \\
\left(\mu \mathrm{g} \mathrm{Sn} \mathrm{L}^{-1}\right)\end{array}$} & \multicolumn{2}{|c|}{ IL-HF-LPME } & \multicolumn{2}{|c|}{ TCILDLPME } \\
\hline & & & Found $^{\mathrm{a}}\left(\mu \mathrm{g} \mathrm{Sn} \mathrm{L}^{-1}\right)$ & Recovery $^{\mathrm{a}}(\%)$ & Found $^{\mathrm{a}}\left(\mu \mathrm{g} \mathrm{Sn} \mathrm{L} \mathrm{L}^{-1}\right)$ & Recovery $^{\mathrm{a}}(\%)$ \\
\hline \multirow{9}{*}{ Tributyltin } & \multirow{3}{*}{ Sea water } & - & $5.4 \pm 0.8$ & & $5.8 \pm 0.5$ & \\
\hline & & 20 & $23.1 \pm 2.7$ & $91.3 \pm 7.6$ & $25.1 \pm 0.8$ & $98.3 \pm 3.7$ \\
\hline & & 30 & $31.7 \pm 3.3$ & $89.7 \pm 8.1$ & $35.6 \pm 1.2$ & $99.2 \pm 4.1$ \\
\hline & \multirow{3}{*}{ Waste water } & - & $4.8 \pm 0.4$ & & $5.6 \pm 0.4$ & \\
\hline & & 20 & $21.8 \pm 2.9$ & $87.6 \pm 7.2$ & $25.3 \pm 0.9$ & $98.6 \pm 4.1$ \\
\hline & & 30 & $29.6 \pm 3.8$ & $85.3 \pm 8.1$ & $35.4 \pm 1.3$ & $99.1 \pm 4.8$ \\
\hline & \multirow{3}{*}{ River water } & - & n.d. & & n.d. & \\
\hline & & 20 & $18.5 \pm 1.1$ & $92.4 \pm 7.4$ & $19.2 \pm 0.8$ & $96.5 \pm 3.2$ \\
\hline & & 30 & $26.5 \pm 2.2$ & $88.4 \pm 7.9$ & $29.2 \pm 1.2$ & $97.2 \pm 3.4$ \\
\hline \multirow{9}{*}{ Triphenyltin } & \multirow{3}{*}{ Sea water } & - & $3.9 \pm 0.4$ & & $3.8 \pm 0.5$ & \\
\hline & & 20 & $20.9 \pm 2.5$ & $87.3 \pm 8.5$ & $18.7 \pm 0.7$ & $93.4 \pm 4.2$ \\
\hline & & 30 & $29.5 \pm 2.7$ & $86.9 \pm 9.2$ & $28.2 \pm 1.4$ & $94.2 \pm 4.6$ \\
\hline & \multirow{3}{*}{ Waste water } & - & n.d. & & n.d. & \\
\hline & & 20 & $17.7 \pm 2.1$ & $88.3 \pm 8.7$ & $18.4 \pm 0.8$ & $92.2 \pm 4.5$ \\
\hline & & 30 & $26.1 \pm 2.3$ & $87.4 \pm 9.6$ & $28.1 \pm 1.5$ & $93.8 \pm 5.2$ \\
\hline & \multirow{3}{*}{ River water } & - & n.d. & & n.d. & \\
\hline & & 20 & $17.8 \pm 2.2$ & $89.7 \pm 7.1$ & $19.3 \pm 0.6$ & $96.7 \pm 3.1$ \\
\hline & & 30 & $26.6 \pm 2.5$ & $88.6 \pm 8.2$ & $28.6 \pm 0.8$ & $95.3 \pm 2.8$ \\
\hline
\end{tabular}

and they have the advantages of being simple, inexpensive and more environmentally friendly sample preparation techniques. However, HS-SDME and HFLPME have some disadvantages: at fast stirring speed, air bubbles are formed leading to reduce extraction efficiency; extraction is timeconsuming and the ionic liquid volume is small. Therefore, the enrichment ability is limited. Meanwhile HS-SDME requires careful and elaborate manual operations.

Limit of detections of TCILDLPME were better than those obtained for HF-LPME and HS-SDME, reflecting that TCILDLPME enables high enrichment of analytes and consequently high sensitivity. The linearity of the calibration plots constructed after analysis of spiked samples were good for these procedures, with correlation coefficients always greater than 0.990. Comparison of LODs showed that the sensitivity of methods was in good shape to ensure reliable determination of these environmental pollutants. HFLPME shows some selectivity, because of the pores in walls of the hollow fiber. Large molecules, which can also be soluble in extraction solvent, may not be extracted. Thus, HFLPME has the potential for selective extraction of analytes from complex matrix such as biological fluids and soil slurry. Consequently, direct determi- nation of analytes is possible. However, TCILDLPME was preferred for analysis of the compounds in many samples, because it has the features of simplified device, simplicity of operation, low LOD, wide linear range, high enrichment factor and very short extraction time, which is far from those of other methods i.e. HFLPME and HS-SDME.

Application to real samples: In order to study the applicability of the proposed methods, experiments were performed with seawater, waste and river water samples. The results are recorded in Table-4. It is interesting to note the relatively good agreement between the results obtained by use of two procedures. The results show that the river water samples were free of tributyltin and triphenyltin contamination. These samples were then spiked with tributyltin and triphenyltin at a concentration of 20 and $30 \mu \mathrm{gL}^{-1}$ to assess matrix effects. The spiked recoveries were very good in the range of 85.3-92.4\% with RSD less than $9.6 \%$ for HF-LPME method and 92.2-99.2\% with RSD less than $5.2 \%$ for TCILDLPME method. Therefore, mainly no matrix interferences were observed. Figs. 5 and 6 show the chromatograms obtained after extraction of the real sample under optimum conditions by HF-LPME and TCILDLPME, respectively. 

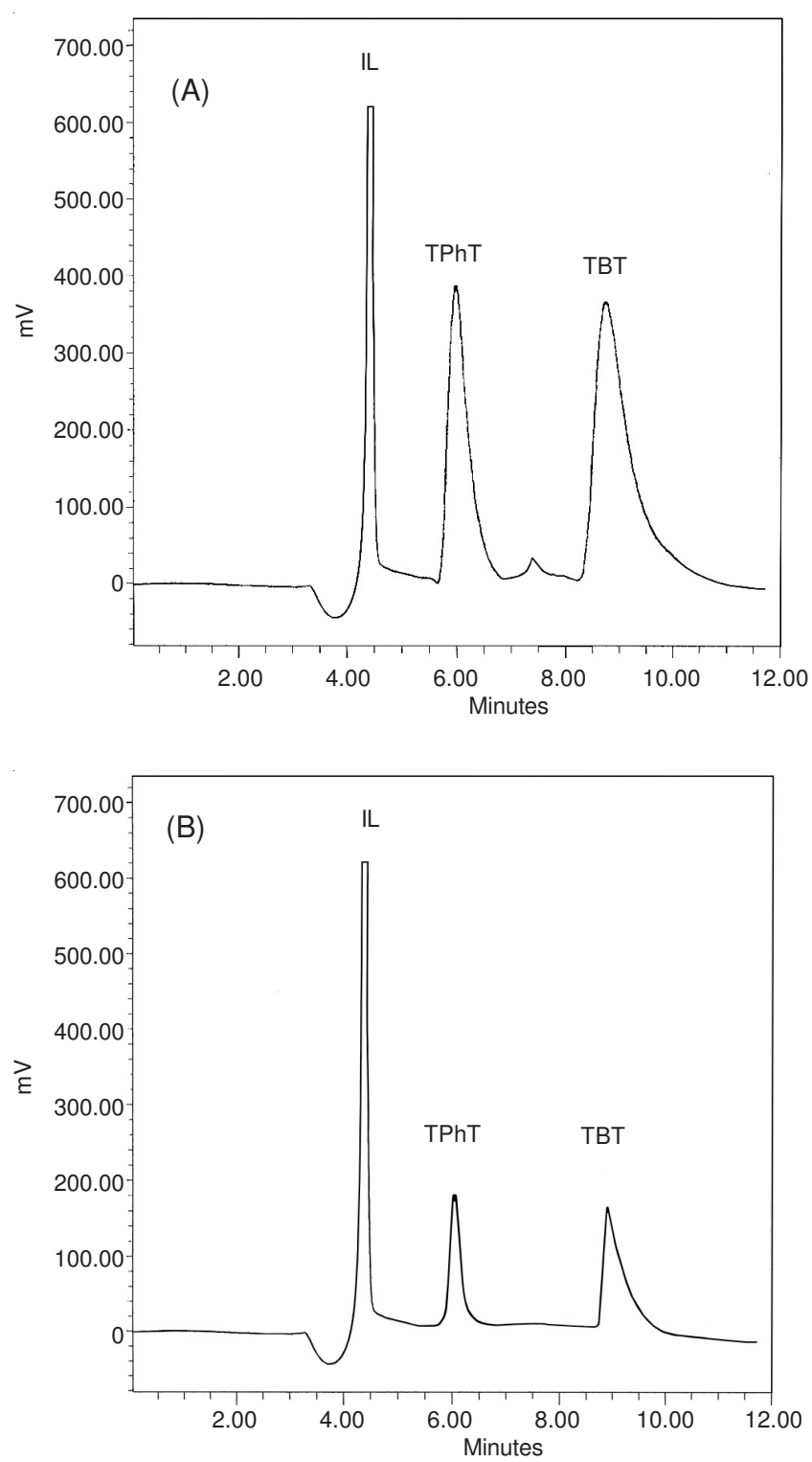

Fig. 5. Chromatograms of a sea water sample obtained by HF-LPME under optimal conditions (A) spiked sample with $50 \mu \mathrm{g} \mathrm{L} \mathrm{L}^{-1}$ of each analyte tributyltin and triphenyltin (B) sample not spiked

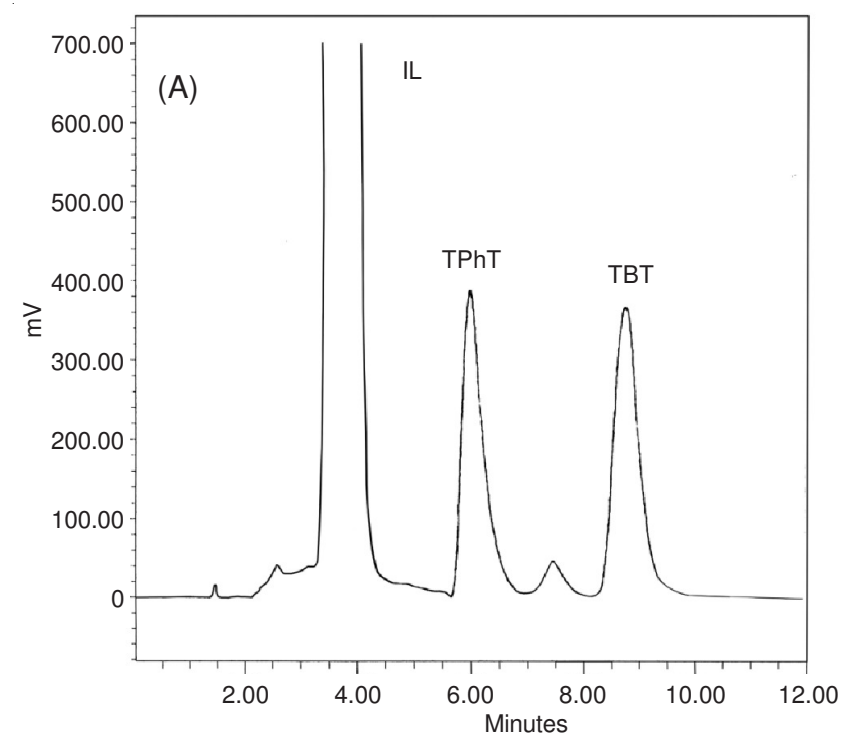

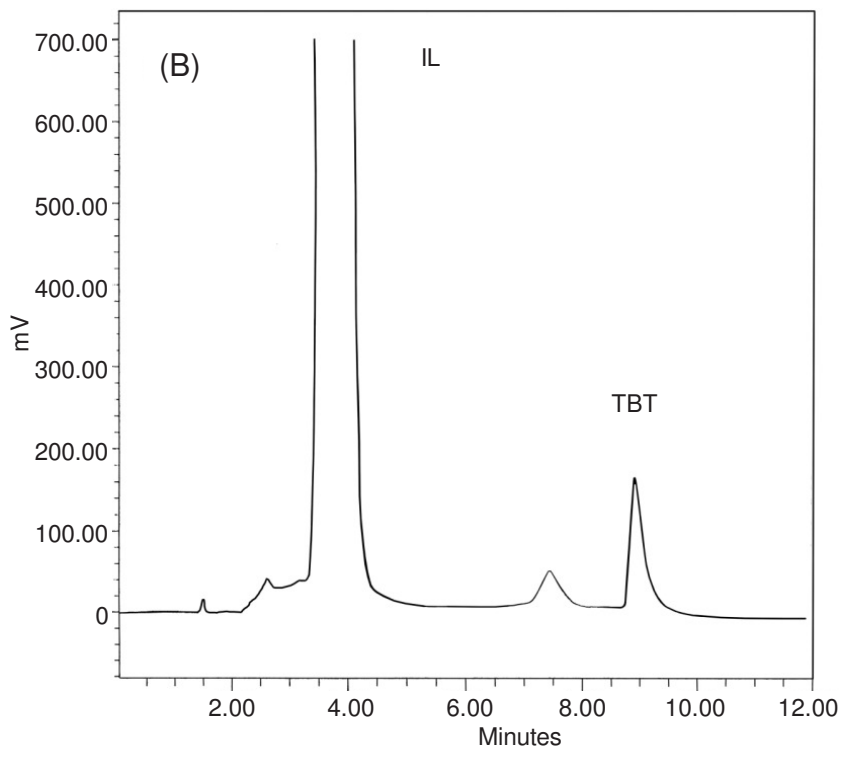

Fig. 6. Chromatograms of a waste water sample obtained by TCILDLPME under optimal conditions (A) spiked sample with $50 \mu \mathrm{g} \mathrm{L}^{-1}$ of each analyte tributyltin and triphenyltin (B) sample not spiked

\section{Conclusion}

TCILDLPME and IL-HF-LPME as green sample preparation techniques were developed and compared with each other and HS-SDME technique. The experimental results demonstrated that high extraction efficiencies were achieved when these techniques were successfully applied to the determination of tributyltin and triphenyltin in environmental water samples employing HPLC-fluorimetric system. In TCILDLPME, the sensitivity could be enhanced with the increase of its volume without the suspending limit of HF-LPME. Meanwhile, the amount of extraction solvent can be changed according to the sample volume. In conclusion, TCILDLPME in comparison with HF-LPME and HS-SDME is simple, inexpensive, low LOD, high recovery, high enrichment factor, very short extraction time and convenient sample preparation technique. These techniques are compatible with a wide range of analytes in biological and environmental samples, which could have the strong platform for analytical microextraction when applied with HPLC in the future.

\section{ACKNOWLEDGEMENTS}

The authors thank Institute of Standards and Industrial Research of Maragheh (Iran) for some experimental help.

\section{REFERENCES}

1. K. Fent, Crit. Rev. Toxicol., 26, 1 (1996).

2. M. Ma and F. Cantwell, Anal. Chem., 70, 3912 (1998).

3. M. Palit, D. Paradasani, A.K. Gupta and D.K. Dubey, Anal. Chem., 77, 711 (2005)

4. H. Serra and J.M.F. Nogueira, J. Chromatogr. A, 1094, 130 (2005).

5. J. Munoz, J.R. Baena, M. Gallego and M. Valcarcel, J. Chromatogr. A, 1023, 175 (2004)

6. N.P. Vela and J.A. Caruso, J. Anal. At. Spectrom., 11, 1129 (1996).

7. M.L. Gac, G. Lespes and M.P. Gautier, J. Chromatogr. A, 999, 123 (2003).

8. F. Sanchez-Rojas, C. Bosch-Ojeda and J.M. Cano-Pavon, Chromatographia, 69, S79 (2003). 
9. V. Colombini, C.B. Montigny, L. Yang, P. Maxwell, R.E. Sturgeon and Z. Mester, Talanta, 63, 555 (2004).

10. H. Shioji, S. Tsunoi, H. Harino and M. Tanaka, J. Chromatogr. A, 1048, 81 (2004).

11. A. Sarafraz-Yazdi and A.H. Amiri, Trends in Anal. Chem., 29, 1 (2010).

12. S.P. Bjergaard and K.E. Rasmussen, J. Chromatogr. A, 1184, 132 (2008).

13. M. Rezaee, Y. Assadi, M.R.M. Hosseni, E. Aghaee, F. Ahmadi and S. Berijani, J. Chromatogr. A, 1116, 1 (2006)

14. A.P. Birjandi, A. Bidari, F. Rezaei, M.R.M. Hosseini and Y. Assadi, J. Chromatogr. A, 1193, 19 (2008).

15. M. Rezaee, Y. Yamini and M. Faraji, J. Chromatogr. A, 1217, 2342 (2010).

16. Q.X. Zhou, H.H. Bai and J.P. Xiao, J. Chromatogr. A, 1177, 43 (2008).

17. H. Zhao, S. Xia and P. Ma, J. Chem. Technol. Biotechnol., 80, 1089 (2005).

18. J. Abulhassani, J. Manzoori and M. Amjadi, J. Hazard. Mater, 176, 481 (2010).

19. J. Manzoori, M. Amjadi and J. Abulhassani, Talanta, 77, 1539 (2009).

20. J.F. Peng, J.F. Liu, G.B. Jiang, C. Tai and M.J. Huang, J. Chromatogr A, 1072, 3 (2005).

21. C.L. Ye, Q.X. Zhou and X.M. Wang, Anal. Chim. Acta, 572, 165 (2006)

22. L. Vidal, A. Chisvert, A. Canals and A. Salvador, J. Chromatogr. A, 1174, 95 (2007).
23. L. Vidal, E. Psillakis, C.E. Domini, N. Grane and F. Marken, Anal. Chim. Acta, 584, 189 (2007).

24. P. Xuejiao, L. Hailu and L. Mingbiao, 3rd International Conference on Bioinformatics and Biomedical Engineering, Art. No. 5162629 (2009).

25. Y. Tao, J.F. Liu, X.L. Hu, H.C. Li, T. Wang and G.B. Jiang, J. Chromatogr. A, 1216, 6259 (2009).

26. J.F. Liu, J.A. Jonsson and G.B. Jiang, Trends Anal. Chem., 24, 20 (2005).

27. S. Pandey, Anal. Chim. Acta, 556, 38 (2006).

28. S.A. Shamsi and N.D. Danielson, J. Sep. Sci., 30, 1729 (2007).

29. F. Pena-Pereira, I. Lavilla and C. Bendicho, Spectrochimica Acta Part $B, 64,1$ (2009)

30. H. Sheikhloie, M.S. Tehrani, P.A. Azar and S.W. Husain, Acta Chromatogr., 21, 577 (2009).

31. A.J. Carmichael and K.R. Seddon, J. Phys. Org. Chem., 13, 591 (2000).

32. J.F. Peng, J.F. Liu, X.L. Hu and G.B. Jiang, J. Chromatogr. A, 1139, 165 (2007).

33. C.G. Arnold, A. Weidenhaupt, M.M. David, S.R. Muller, S.B. Haderlein and R.P. Schwarzenbach, Environ. Sci. Technol., 31, 2596 (1997).

34. G. Shen and H.K. Lee, Anal. Chem., 74, 648 (2002).

35. K.E. Rasmussen, S.P. Bjergaard, M. Krogh, H.G. Ugland and T. Gronhaug, J. Chromatogr. A, 873, 3 (2000)

36. M. Baghdadi and F. Shemirani, Anal. Chim. Acta, 613, 56 (2008). 